\section{Commentary: Multivalve infective endocarditis: Further support for radical debridement and complex reconstruction}

\author{
Leonard N. Girardi, MD, and Christopher Lau, MD
}

Surgery for infective endocarditis of the aortic root and surrounding structures remains a condition associated with high mortality. Even in the hands of experienced surgeons, the radical debridement required to completely excise infected tissue oftentimes leaves one with the need for complex patch reconstruction of the intervalvular fibrosa. ${ }^{1}$ Autologous pericardium or bovine pericardial patches are commonly used to re-establish the aortic, mitral, or tricuspid annulus before proceeding with either valve repair or replacement. The mortality associated with these procedures remains quite formidable despite improvements in surgical technique, antibiotics, and perioperative care.

In this issue of JTCVS Techniques, Jayanyar and colleagues ${ }^{2}$ present a case report of a young patient presenting with combined aortic and tricuspid valve endocarditis with destruction of the intervalvular fibrosa. They provide the readers with clear intraoperative photographs and a video of the most critical portions of the procedure, the reestablishment of continuity of the fibrous trigone shared by the aortic and tricuspid valves. There is an emphasis that this is a "transaortic-approach only" technique, but in reality, there is a generous right atriotomy that permits the visualization of the tricuspid valve necessary to carry out a complex tricuspid valve repair. Information is not given on any perioperative complications associated with this procedure, but the authors did confirm a gratifying 5-year survivor following this extensive operation.

From the Department of Cardiothoracic Surgery, Weill Cornell Medicine, New York, NY.

Disclosures: The authors reported no conflicts of interest.

The Journal policy requires editors and reviewers to disclose conflicts of interest and to decline handling or reviewing manuscripts for which they may have a conflict of interest. The editors and reviewers of this article have no conflicts of interest.

Received for publication Oct 10, 2021; revisions received Oct 10, 2021; accepted for publication Oct 21, 2021; available ahead of print Oct 26, 2021.

Address for reprints: Leonard N. Girardi, MD, Department of Cardiothoracic Surgery,

Weill Cornell Medicine, 525 East 68th St, M-424, New York, NY 10021 (E-mail:

lngirard@med.cornell.edu).

JTCVS Techniques 2021;10:307-8

2666-2507

Copyright (C) 2021 The Author(s). Published by Elsevier Inc. on behalf of The American Association for Thoracic Surgery. This is an open access article under the CC BY-NC-ND license (http://creativecommons.org/licenses/by-nc-nd/4.0/).

https://doi.org/10.1016/j.xjtc.2021.10.043

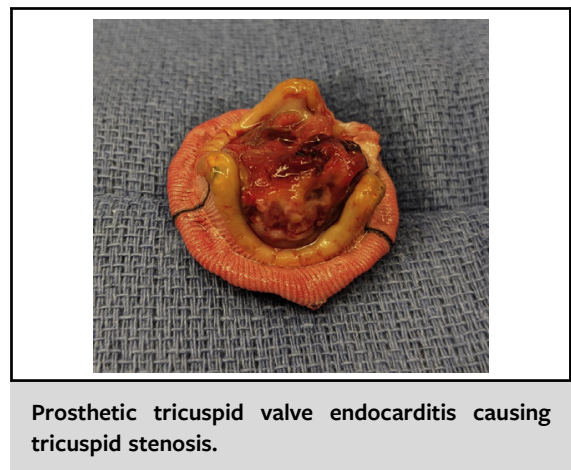

CENTRAL MESSAGE

Surgery for infective endocarditis of the aortic root and intervalvular fibrosa requires extensive debridement, and complex reconstruction of the fibrous structure of the heart is necessary.

It was interesting to see that the authors did not obtain advanced imaging such as a transesophageal echocardiogram before proceeding with surgery. It is true that the preoperative transthoracic echocardiogram suggested both aortic and tricuspid valve involvement. However, given the extensive tissue destruction often seen with Staphylococcus aureus infection (and the significant increase in operative mortality associated with this bacterium), a transesophageal echocardiogram before proceeding may permit surgeons to develop a more detailed perioperative plan that includes the involvement of surgeons experienced with advanced aortic root reconstructive and valve repair techniques. ${ }^{3}$

Even in experienced hands like those of the senior authors on this case report, the operative mortality and longterm outcomes associated with infective endocarditis and reconstruction of the intervalvular fibrosa support cautious optimism when taking on these cases. In a recently published series of 127 consecutive patients undergoing such procedures in an experienced center, the 30-day mortality was $28.3 \%$, with a 90 -day mortality of $37 \%$. Five-year survival was $41.8 \%$, and the presence of $S$ aureus was predictive of a greater mortality on multivariable analysis (odds ratio, 1.65; $P=.04$ ). Similar results were reported from experienced surgeons here in the United States as well. ${ }^{5}$ Fortunately, if one can have obtain a technically sound result using techniques like those presented in this 
report, less than $6 \%$ of patients ${ }^{4}$ will go on to develop recurrent endocarditis that requires a reoperation.

\section{References}

1. David TE, Juo J, Armstrong S. Aortic and mitral valve replacement with reconstruction of the intervalvular fibrous body. J Thorac Cardiovasc Surg. 1997;114: 766-72.

2. Jayanyar J, Aphram G, De Kerchove L, El Khoury G. Transaortic approach for combined aorto-tricuspid valve endocarditis. J Thorac Cardiovasc Surg Tech 2021; 10:302-5.
3. Pettersson GB, Coselli JS, Hussain ST, Griffin B, Blackstone EH, Gordon SM, et al. 2016 the American Association for Thoracic Surgery (AATS) consensus guidelines: surgical treatment of infective endocarditis: executive summary. $J$ Thorac Cardiovasc Surg. 2017;153:1241-58.

4. Davierwala PM, Marin-Cuartas M, Misfeld M, Deo SV, Lehmann S, Garbade J, et al. Five-year outcomes following complex reconstructive surgery for infective endocarditis involving the intervalvular fibrous body. Eur J Cardiothorac Surg. 2020;58:1080-7

5. Navia JL, Eigharably H, Hakin AH, Witten JC, Haupt MJ, Germano E, et al. Longterm outcomes of surgery for invasive valvular endocarditis involving the aortomitral fibrosa. Ann Thorac Surg. 2019;108:1314-23. 